\title{
Contrasting size-resolved hygroscopicity of fine particles derived by HTDMA and HR-ToF-AMS measurements between summer and winter in Beijing: the impacts of aerosol aging and local emissions
}

\author{
Xinxin Fan ${ }^{1, *}$, Jieyao Liu ${ }^{1}{ }^{*}$, Fang Zhang ${ }^{1}$, Lu Chen ${ }^{1}$, Don Collins ${ }^{2}$, Weiqi Xu ${ }^{3,4}$, Xiaoai Jin ${ }^{1}$, Jingye Ren ${ }^{1}$, \\ Yuying Wang ${ }^{1,5}$, Hao $\mathrm{Wu}^{1}$, Shangze $\mathrm{Li}^{1}$, Yele Sun ${ }^{3,4}$, and Zhanqing $\mathrm{Li}^{6}$ \\ ${ }^{1}$ College of Global Change and Earth System Science, Beijing Normal University, Beijing 100875, China \\ ${ }^{2}$ Department of Chemical and Environmental Engineering, University of California Riverside, Riverside, California, USA \\ ${ }^{3}$ State Key Laboratory of Atmospheric Boundary Layer Physics and Atmospheric Chemistry, \\ Institute of Atmospheric Physics, Chinese Academy of Sciences, Beijing 100029, China \\ ${ }^{4}$ College of Earth Sciences, University of Chinese Academy of Sciences, Beijing 100049, China \\ ${ }^{5}$ School of Atmospheric Physics, Nanjing University of Information Science and Technology, Nanjing 210044, China \\ ${ }^{6}$ Earth System Science Interdisciplinary Center and Department of Atmospheric and Oceanic Science, \\ University of Maryland, College Park, Maryland, USA \\ *These authors contributed equally to this work.
}

Correspondence: Fang Zhang (fang.zhang@bnu.edu.cn)

Received: 19 June 2019 - Discussion started: 25 June 2019

Revised: 11 December 2019 - Accepted: 18 December 2019 - Published: 24 January 2020

\begin{abstract}
The effects of aerosols on visibility through scattering and absorption of light and on climate through altering cloud droplet concentration are closely associated with their hygroscopic properties. Here, based on field campaigns in winter and summer in Beijing, we compare the size-resolved hygroscopic parameter $\left(\kappa_{\mathrm{gf}}\right)$ of ambient fine particles derived by an HTDMA (hygroscopic tandem differential mobility analyzer) to that (denoted as $\kappa_{\text {chem }}$ ) calculated by an HR-ToFAMS (high-resolution time-of-flight aerosol mass spectrometer) measurements using a simple rule with the hypothesis of uniform internal mixing of aerosol particles. We mainly focus on contrasting the disparity of $\kappa_{\mathrm{gf}}$ and $\kappa_{\mathrm{chem}}$ between summer and winter to reveal the impact of atmospheric processes/emission sources on aerosol hygroscopicity and to evaluate the uncertainty in estimating particle hygroscopicity with the hypothesis. We show that, in summer, the $\kappa_{\text {chem }}$ for 110,150 , and $200 \mathrm{~nm}$ particles was on average $\sim 10 \%-$ $12 \%$ lower than $\kappa_{\mathrm{gf}}$, with the greatest difference between the values observed around noontime when aerosols experience rapid photochemical aging. In winter, no apparent disparity between $\kappa_{\text {chem }}$ and $\kappa_{\mathrm{gf}}$ is observed for those $>100 \mathrm{~nm}$ particles around noontime, but the $\kappa_{\text {chem }}$ is much higher than
\end{abstract}

$\kappa_{\mathrm{gf}}$ in the late afternoon when ambient aerosols are greatly influenced by local traffic and cooking sources. By comparing with the observation from the other two sites (Xingtai, Hebei and Xinzhou, Shanxi) of north China, we verify that atmospheric photochemical aging of aerosols enhances their hygroscopicity and leads to $10 \%-20 \%$ underestimation in $\kappa_{\text {chem }}$ if using the uniform internal mixing assumption. The effect is found more significant for these $>100 \mathrm{~nm}$ particles observed in remote or clean regions. The lower $\kappa_{\text {chem }}$ likely resulted from multiple impacts of inappropriate application of the density and hygroscopic parameter of organic aerosols in the calculation, as well as influences from chemical interaction between organic and inorganic compounds on the overall hygroscopicity of mixed particles. We also find that local/regional primary emissions, which result in a large number of externally mixed BC (black carbon) and POA (primary organic aerosol) in urban Beijing during traffic rush hour time, cause a $20 \%-40 \%$ overestimation of the hygroscopic parameter. This is largely due to an inappropriate use of density of the BC particles that is closely associated with its morphology or the degree of its aging. The results show that the calculation can be improved by applying an effec- 
tive density of fresh $\mathrm{BC}\left(0.25-0.45 \mathrm{~g} \mathrm{~cm}^{-3}\right)$ in the mixing rule assumption. Our study suggests that it is critical to measure the effective density and morphology of ambient BC, in particular in those regions with influences of rapid secondary conversion/aging processes and local sources, so as to accurately parameterize the effect of $\mathrm{BC}$ aging on particle hygroscopicity.

\section{Introduction}

The effects of aerosols on visibility through scattering and absorption of light and on climate through altering cloud droplet concentration are influenced by their hygroscopic growth. Understanding and reducing the uncertainty in prediction of the aerosol hygroscopic parameter $(\kappa)$ using chemical composition would improve model predictions of aerosol effects on clouds and climate.

The hygroscopic properties of both the natural and anthropogenic aerosols, in addition to being affected by its chemical composition (Gunthe et al., 2009), are also affected by the particle mixing state and aging (Schill et al., 2015; Peng et al., 2017a). For example, a recent laboratory study showed that the coexisting hygroscopic species have a strong influence on the phase state of particles, thus affecting chemical interactions between inorganic and organic compounds as well as the overall hygroscopicity of mixed particles (C. Peng et al., 2016). The field measurements also demonstrated that the hydrophobic black carbon particles became hygroscopic with atmospheric mixing and aging by organics (i.e., Peng et al., 2017a). In a heavily polluted atmosphere with varied aerosol sources and sinks as well as complex physical and chemical processes, the mixing state and its impact on aerosol hygroscopicity is more complicated. The hygroscopicity of mixed particles and mutual impacts between the components are still poorly understood.

Previous studies have presented the difference between the $\kappa$ obtained from HTDMA or CCNc (cloud condensation nuclei counter) measurements and that calculated based on the volume mixing ratio of chemical components. Laboratory results from Cruz and Pandis (2000) indicate that $\kappa_{\mathrm{gf}}$ of internally mixed ammonium sulfate and organic matter is higher than $\kappa_{\text {chem }}$ calculated for assumed uniform internal mixing. But C. Peng et al. (2016) found that, for sodium chloride and organic aerosol mixed particles, the measured growth factors by HTDMA were significantly lower than calculations from the mixing rule methods. In some field studies on aged aerosols, the $\kappa$ was underestimated by the calculation based on a uniform internal mixing assumption, and they thus lead to an underestimation of $\mathrm{CCN}$ concentration (Bougiatioti, et al., 2009; Chang et al., 2007; Kuwata et al., 2008; Wang et al., 2010; Ren et al., 2018). However, during primary-emissiondominated periods, the $\kappa$ value from calculations based on bulk chemical composition was much higher than that mea- sured by HTDMA measurements (Zhang et al., 2017). The various results from previous studies suggest distinct effects of aerosol mixing state on their hygroscopicity. Overall, (i) to what extent the differences depend on the mixing state and the extent of aging of the particles and (ii) how the different atmospheric processes and what kinds of mixing structure of the particles may result in the disparity between the measured and calculated hygroscopic parameter have not been clearly clarified by the previous studies. A comprehensive investigation on the causes and magnitude of the effect is of great significance to parameterize the effect of atmospheric processes/emissions of aerosols on particle hygroscopicity in models.

In the atmosphere, the $\kappa$, which is related to the particle mixing state diversity, varies largely across the size range of ambient fine particles (Rose et al., 2010). However, previous studies just compared the $\kappa$ calculated from bulk chemical composition to that measured by HTDMA (Zhang et al., 2017). Using size-resolved, not bulk chemical composition measurements in different seasons is expected to provide a more comprehensive understanding and insights into how the aerosol mixing state influences their hygroscopicity, motivating our analysis that employs size-resolved chemical composition measured by a high-resolution time-of-flight aerosol mass spectrometer (HR-ToF-AMS) in this study. The aim of this paper is to study the hygroscopicity and mixing state characteristics of fine particles in the Beijing urban area, as well as to reveal the impact of atmospheric processes/sources and mixing/aging on aerosol hygroscopicity and elucidate the uncertainty in calculating the hygroscopic parameter using simple mixing rule estimates based on sizeresolved chemical composition. The experiment and theory in the study are introduced in Sect. 2. The comparison between the hygroscopic parameter obtained from the HTDMA (hygroscopic tandem differential mobility analyzer) and that calculated using size-resolved chemical composition is discussed in Sect. 3. Conclusions from the study are given in Sect. 4.

\section{Experiment and theory}

\subsection{Site and instruments}

Two field campaigns are conducted during winter 2016 and summer 2017 of urban Beijing (Fig. 1, BJ: $39.97^{\circ} \mathrm{N}$, $116.37^{\circ} \mathrm{E}$ ) for measurements of aerosol physical and chemical properties. The BJ site is located at the Institute of Atmospheric Physics (IAP), Chinese Academy of Sciences, which is between the north Third Ring Road and Fourth Ring Road in northern Beijing. Local traffic and cooking emissions can be important at the site (Sun et al., 2015). The sampling period in the cold season was from 16 November to 10 December 2016, during the domestic heating period in Beijing. 


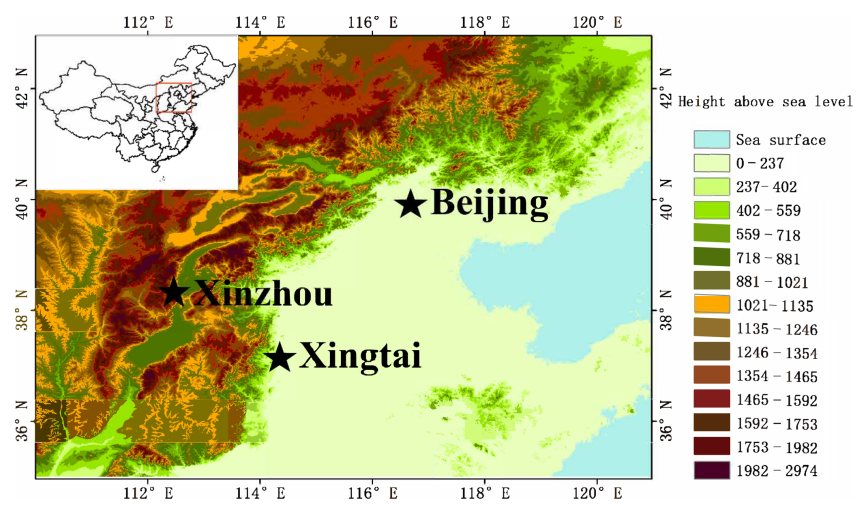

Figure 1. The map location of the sites.

The sampling period in the warm season was from 25 May to 18 June 2017.

The particle number size distribution (PNSD) in the size range from 10 to $550 \mathrm{~nm}$ was measured with a scanning mobility particle sizer (SMPS; Wang and Flagan, 1990; Collins et al., 2002), which consists of a long differential mobility analyzer (DMA, model 3081L, TSI Inc.) to classify the particle and a condensation particle counter (CPC, model 3772, TSI Inc.) to detect the size-classified particles. The sampled particles were dried to a relative humidity $<30 \%$ before entering the DMA. The measurement time for each size distribution was 5 min.

The HTDMA system used in this study has been described in detail in previous publications (Tan et al., 2013; Wang et al., 2017; Zhang et al., 2017). Here, only a brief description is given. A Nafion dryer dried the sampled particles to a relative humidity $<20 \%$, after which the steady-state charge distribution was reached in a bipolar neutralizer. The first differential mobility analyzer $\left(\mathrm{DMA}_{1}\right.$, model $3081 \mathrm{~L}$, TSI Inc.) selected the quasi-monodisperse particles by applying a fixed voltage. The dry diameters selected in this study were 40 , $80,110,150$, and $200 \mathrm{~nm}$. The quasi-monodisperse particles were humidified to a controlled RH ( $90 \%$ in this study) using a Nafion humidifier. A second DMA (DMA 2 , same model as the $\mathrm{DMA}_{1}$ ) coupled with a water-based condensation particle counter (WCPC, model 3787, TSI Inc.) measured the particle number size distributions of the humidified aerosol. RH calibration with ammonium sulfate was carried out regularly during the study.

The hygroscopic growth factor (Gf) is defined as the ratio of the mobility diameter at a given RH to the dry diameter:

$\mathrm{Gf}=\frac{D(\mathrm{RH})}{D(\text { dry })}$.

The Gf probability density function (PDF) is retrieved based on the TDMA ${ }_{\text {inv }}$ algorithm developed by Gysel et al. (2009). Dry scans in which the RH between the two DMAs was not increased were used to define the width of the transfer function.
Size-resolved nonrefractory submicron aerosol composition was measured with an Aerodyne high-resolution timeof-flight aerosol mass spectrometer (HR-ToF-AMS; Xu et al., 2015). The particle mobility diameter was estimated by dividing the vacuum aerodynamic diameter from the AMS measurements by particle density. Because the uncertainty caused by the fixed density across the size range is negligible (Wang et al., 2016), here, the particle density is assumed to be $1600 \mathrm{~kg} \mathrm{~m}^{-3}$ (Zamora et al., 2019). AMS positive matrix factorization (PMF) with the PMF2.exe (v4.2) method was performed to identify various factors of organic aerosols. Xu et al. (2015) have described the operation and calibration of the HR-ToF-AMS in detail. Black carbon (BC) mass concentration was derived from measurements of light absorption with a seven-wavelength aethalometer (AE33, Magee Scientific Corp.; Zhao et al., 2017).

\subsection{Data}

The time series of the submicron particle mass concentration $\mathrm{PM}_{1}$, bulk mass concentrations of the main species in $\mathrm{PM}_{1}$, mass fraction of the chemical composition of $\mathrm{PM}_{1}$, and probability density function of growth factor (Gf PDFs) for 40 and $150 \mathrm{~nm}$ particles during the campaign are presented in Fig. 2. Quite distinct temporal variability of aerosol chemical and physical properties was observed between winter and summer. The average mass concentration of $\mathrm{PM}_{1}$ was $55.2 \mu \mathrm{g} \mathrm{m}^{-3}$ in the winter and $16.5 \mu \mathrm{g} \mathrm{m}^{-3}$ in the summer during our study periods. In this study, we define the conditions when the mass concentration in winter period was $<20$ and $>80 \mu \mathrm{g} \mathrm{m}^{-3}$ for clean and polluted conditions, respectively. Organic aerosol (OA), consisting of secondary organic aerosol (SOA) and primary organic aerosol (POA), was the major fraction during both the winter and summer sampling periods. POA concentration was higher than that of SOA in the winter, which reflects the influence of primary emissions such as coal combustion OA (COOA) in Beijing (Hu et al., 2016; Sun et al., 2016). In contrast, SOA usually dominated in the summer, which is evidence that secondary aerosol formation played a key role in the source of $\mathrm{PM}_{1}$. Distinct hydrophobic (with Gf of $\sim 1.0$ ) and more hygroscopic (with Gf of $\sim 1.5$ ) modes were observed from Gf PDFs of both small and large particles. Sometimes the more hygroscopic mode particles were more concentrated, and at other times the hydrophobic particles were. In general though, the more hygroscopic mode dominated for larger particles (i.e., $150 \mathrm{~nm}$ ), and the less hygroscopic mode did for the smallest particles (e.g., $40 \mathrm{~nm}$ ). Occasionally, only the hydrophobic mode was evident for $150 \mathrm{~nm}$ particles, which occurred when POA dominated the $\mathrm{PM}_{1}$. Only the hygroscopic mode was discernable for $40 \mathrm{~nm}$ particles during new particle formation (NPF) events that occurred more frequently in summer than winter (Fig. 3). 
Winter

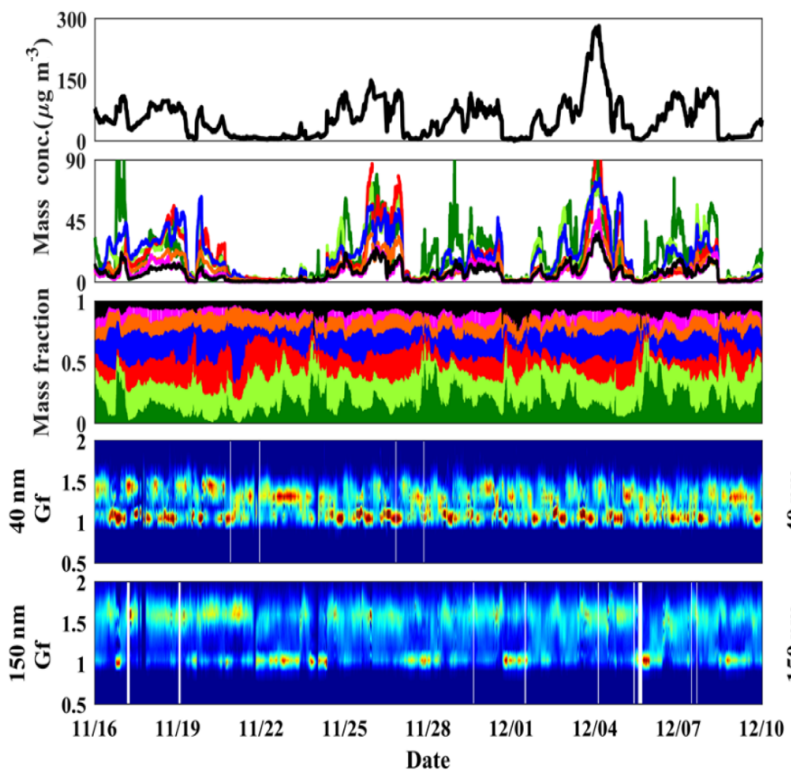

Summer

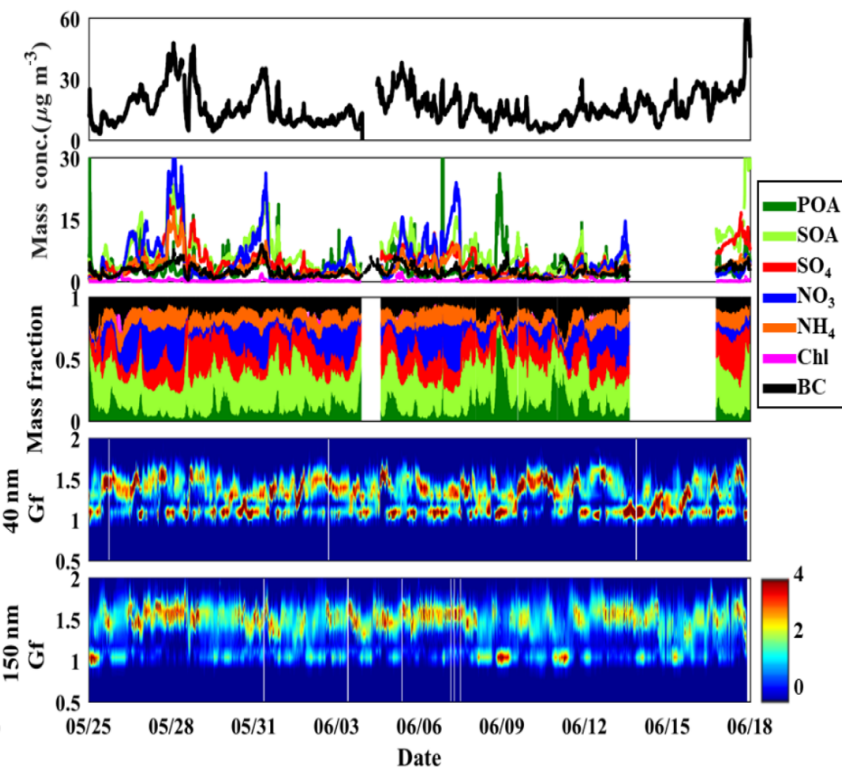

Figure 2. Winter (left) and summer (right) time series of mass concentration of $\mathrm{PM}_{1}$, bulk mass concentration of the main species in $\mathrm{PM}_{1}$, mass fraction of the chemical composition of $\mathrm{PM}_{1}$, and Gf PDFs for 40 and $150 \mathrm{~nm}$ particles.

\subsection{Theory and method}

\subsubsection{Derivation of the hygroscopic parameter, $\kappa$, from the growth factor $(\mathbf{G f})$}

According to $\kappa$-Köhler theory (Petters and Kreidenweis, 2007), the hygroscopicity parameter $\kappa$ can be derived using the growth factor measured by an HTDMA.

$\kappa=\left(\mathrm{Gf}^{3}-1\right)\left(\frac{\exp \left(\frac{A}{D_{\mathrm{d}} \mathrm{Gf}}\right)}{\mathrm{RH}}-1\right)$,

$\mathrm{A}=\frac{4 \sigma_{\mathrm{s} / \mathrm{a}} M_{\mathrm{w}}}{R T \rho_{\mathrm{W}}}$

where Gf is hygroscopic growth factor measured by HTDMA, $D_{\mathrm{d}}$ is the dry diameter of the particles, RH is the relative humidity in the HTDMA ( $90 \%$, in our study), $\sigma_{\mathrm{s} / \mathrm{a}}$ is the surface tension of the solution/air (assumed here to be the surface tension of pure water, $\left.\sigma_{\mathrm{s} / \mathrm{a}}=0.0728 \mathrm{~N} \mathrm{~m}^{-2}\right), M_{\mathrm{w}}$ is the molecular weight of water, $R$ is the universal gas constant, $T$ is the absolute temperature, and $\rho_{\mathrm{w}}$ is the density of water.

\subsubsection{Derivation of the hygroscopic parameter, $\kappa$, from chemical composition data}

For an assumed internal mixture, $\kappa$ can also be calculated by a simple mixing rule on the basis of chemical volume fractions (Petters and Kreidenweis, 2007; Gunthe et al., 2009):

$\kappa_{\mathrm{chem}}=\sum_{i} \varepsilon_{i} \kappa_{i}$, where $\kappa_{i}$ and $\varepsilon_{i}$ are the hygroscopicity parameter and volume fraction for the individual (dry) component in the mixture, respectively. The AMS provides mass concentrations of organics and of many inorganic ions. The inorganic components mainly consisted of $\left(\mathrm{NH}_{4}\right)_{2} \mathrm{SO}_{4}$ and $\mathrm{NH}_{4} \mathrm{NO}_{3}$ (Zhang et al., 2014). And the values of $\kappa$ are 0.48 for $\left(\mathrm{NH}_{4}\right)_{2} \mathrm{SO}_{4}$ and 0.58 for $\mathrm{NH}_{4} \mathrm{NO}_{3}$ (Petters and Kreidenweis, 2007). To estimate $\kappa_{\text {org }}$, we used the following linear function derived by Mei et al. (2013): $\kappa_{\text {org }}=2.10 \times f_{44}-0.11$. We derived the volume fraction of each species by dividing mass concentration by its density. The densities are $1.77 \mathrm{~g} \mathrm{~cm}^{-3}$ for $\left(\mathrm{NH}_{4}\right)_{2} \mathrm{SO}_{4}$ and $1.72 \mathrm{~g} \mathrm{~cm}^{-3}$ for $\mathrm{NH}_{4} \mathrm{NO}_{3}$. The densities of organics are assumed to be $1.2 \mathrm{~g} \mathrm{~cm}^{-3}$ (Turpin and Lim, 2001). The $\kappa$ and density of $\mathrm{BC}$ are assumed to be 0 and $1.7 \mathrm{~g} \mathrm{~cm}^{-3}$. In the following discussions, $\kappa_{\mathrm{gf}}$ and $\kappa_{\mathrm{chem}}$ denote the values derived from HTDMA measurements and calculated using the Zdanovskii-Stokes-Robinson mixing rule (Stokes and Robinson, 1966), respectively.

In addition, we also compare the results from the field campaigns with those from the other two sites, Xingtai (XT: $37.18^{\circ} \mathrm{N}-114.37^{\circ} \mathrm{E}$ ) and Xinzhou (XZ: $38.24^{\circ} \mathrm{N}-$ $112.43^{\circ} \mathrm{E}$ ), in the North China Plain (Fig. 1). At the XZ site, we use the hygroscopic parameter (defined as $\kappa_{\mathrm{CCNc}}$ ) from size-resolved CCN measurements (Zhang et al., 2014, 2016) for comparison. More detailed descriptions of the method to retrieve $\kappa_{\mathrm{CCNc}}$ can be found in Petters and Kreidenweis (2007). Both of the $\kappa_{\mathrm{gf}}$ and $\kappa_{\mathrm{CCNc}}$ are derived based on $\kappa$-Köhler theory (Petters and Kreidenweis, 2007). But, different from the $\kappa_{\mathrm{gf}}$ measured by the HTDMA system which is operated at a $\mathrm{RH}$ of $90 \%$, the $\kappa_{\mathrm{CCNc}}$ is derived by mea- 
suring aerosol CCN activity under the condition of supersaturations with relative humidity of $>100 \%$. Previous studies from field measurements and laboratory experiments showed that the $\kappa_{\mathrm{CCNc}}$ is generally slightly larger or smaller than $\kappa_{\mathrm{gf}}$, but they are basically comparable and can well represent an overall aerosol hygroscopicity (e.g., Carrico et al., 2008; Wex et al., 2009; Good et al., 2010; Irwin et al., 2010; Cerully et al., 2011; Wu et al., 2013; Zhang et al., 2017).

\section{Results and discussion}

\subsection{Diurnal variations of ambient-fine-particle physiochemical properties and hygroscopic growth factor}

The diurnal variations of the PNSD, mass concentration of $\mathrm{PM}_{1}$, mass concentration and fraction of chemical components in $\mathrm{PM}_{1}$, and Gf PDFs for 40 and $150 \mathrm{~nm}$ particles during the campaign are shown in Fig. 3. During the summer an obvious peak value in the PNSD is observed around noontime due to NPF events that typically started around 10:00 LT (local time). The resulting sharp increase in number concentration of nucleation mode particles was followed by decreased concentration and a rapid growth in diameter of the particles along with increased mass concentration of SOA and sulfate in $\mathrm{PM}_{1}$, indicating strong photochemical and secondary formation processes during daytime in the summer (Peng et al., 2017b; shown by the red box in Fig. 3). In contrast, NPF was not evident during the winter period, which may in part be due to the much higher $(\sim 3 \times) \mathrm{PM}_{1}$ mass concentrations in the winter than in the summer. Note that peak values in number concentration and in mass concentrations of $\mathrm{PM}_{1}$ and POA occurred during the early evening (17:0021:00 LT), indicating the strong impact of local sources from traffic emissions and cooking (shown by the black box in Fig. 3; Peng et al., 2014). In addition, the diurnal cycles of aerosol physical and chemical properties are also influenced by the diurnal changes in the planetary boundary layer (PBL) that lead to the accumulation of particles during nighttime when higher values of both number and mass concentration were observed.

Owing to the continued local and primary emissions near the study site, the Gf PDFs for $40 \mathrm{~nm}$ particles generally display a bimodal shape with more and less hygroscopic modes (with Gf of $\sim 1.5$ and $\sim 1.1$ respectively) throughout the day in both winter and summer periods, indicating an external mixing state for the $40 \mathrm{~nm}$ particles. Note that, during nighttime and early morning in the winter, the more hygroscopic mode dominated and was shifted to higher Gf than during the daytime. This is thought to be due to heterogeneous/aqueous reactions on preexisting primary small particles and/or coagulation/condensation processes that are enhanced at night under lower ambient temperature and higher relative humidity, all of which result in a more hygroscopic and more inter- nally mixed aerosol (Liu et al., 2011; Massling et al., 2005; Ye et al., 2013; Wu et al., 2016; Wang et al., 2018a). Interestingly, in the summer period, the concentration of the hydrophilic mode increased quickly around noontime and in the early afternoon (12:00-16:00), with a corresponding decrease in the relative concentration of the hydrophobic mode, which likely indicates a transformation of the particles from an externally mixing state to an internally mixing state as a result of the species condensation from the photochemical reaction (Wu et al., 2016; Wang et al., 2017), resulting in an increase in particle hygroscopicity. In addition, it is evident that $40 \mathrm{~nm}$ particles after 12:00 were dominated by NPF (Fig. 3). Therefore, the increase of hydrophobic mode particles suggests that a large amount of hydrophilic particles are generated from NPF. For $150 \mathrm{~nm}$ particles, the hygroscopic mode in the Gf PDF is more dominant during daytime, in particular during the summer period when the strong solar radiation promotes photochemical aging and growth, thus producing a more internally mixed aerosol. The dominant hydrophobic mode at around 18:00 was observed in both winter and summer and reflects abundant traffic emissions and cooking sources (primarily with POA) during the early evening period.

\section{$3.2 \kappa_{\mathrm{gf}}$ dependence on $D_{\mathrm{p}}$}

The size dependence of particle hygroscopicity parameters for the winter and summer periods is presented in Fig. 4. In the winter, the $40 \mathrm{~nm}$ particles were the least hygroscopic, and the hygroscopicity of larger particles $(>80 \mathrm{~nm})$ displayed an insignificant dependence on particle size. The size independence for the larger particles is consistent with the observed similarity in mass fractions of inorganic and organic species across the size range as shown in the pie charts in Fig. 4a. A similar dependence of particle hygroscopicity on particle size was also observed in the urban area of Beijing during the wintertime of 2014 (Wang et al., 2018b). In the summer, hygroscopicity increased with increasing particle size, which is expected based on the size-dependent patterns shown in the pie charts, with the mass fraction of POA decreasing with the particles size and the mass fraction of inorganics like sulfate and nitrate increasing with particle size.

\subsection{Closure of HTDMA and chemical-composition-derived $\kappa$}

A closure study was conducted between $\kappa_{\text {chem }}$ and $\kappa_{\mathrm{gf}}$ (Fig. 5) to investigate the uncertainty of the two methods, and especially to further illustrate whether particle hygroscopicity can be well predicted by $\kappa_{\text {chem }}$ calculated by assuming internal mixing. Since a size-resolved BC mass concentration measurement was not available during the campaign, we use the bulk mass fraction of $\mathrm{BC}$ particles measured by the AE33 combining with size-resolved BC distribution measured by a single particle soot photometer (SP2) in Beijing 

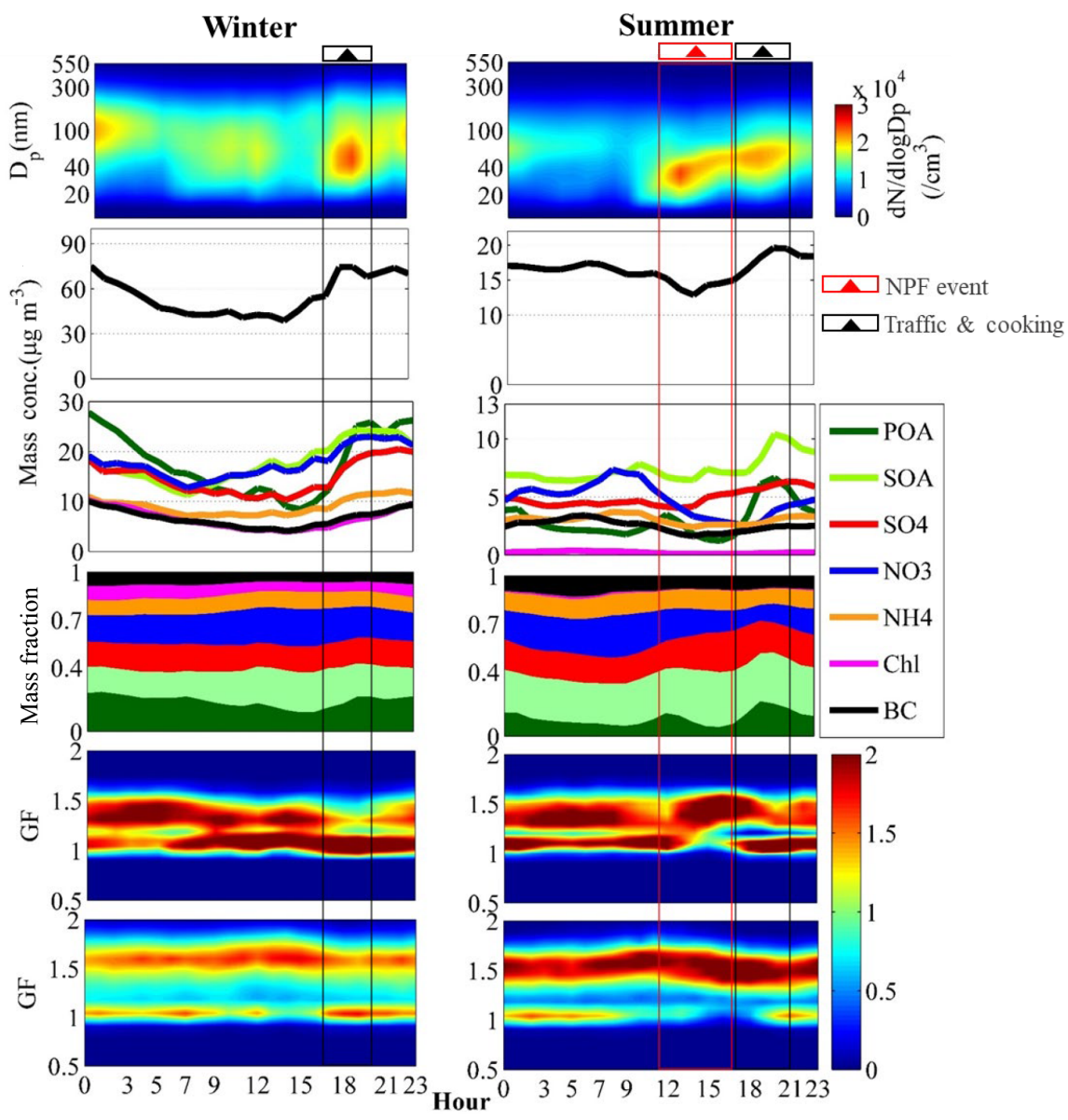

Figure 3. Campaign averaged diurnal variations in particle number size distribution; mass concentration of $\mathrm{PM}_{1}$, bulk mass concentration of main species in $\mathrm{PM}_{1}$, and mass fraction of chemical composition of $\mathrm{PM}_{1}$; and Gf PDFs for 40 and $150 \mathrm{~nm}$ particles in winter (left panels) and summer (right panels) measured in urban Beijing.

(Liu et al., 2019) to estimate $\kappa_{\text {chem }}$. During the calculation, the BC core diameter measured by SP2 has been converted to the diameter of coated $\mathrm{BC}$ particles by multiplying factors of 1.4 and 2.6 under clean (with bulk BC mass concentrations $<2 \mu \mathrm{g} \mathrm{m}^{-3}$ ) and polluted (with bulk BC mass concentrations $>2 \mu \mathrm{g} \mathrm{m}^{-3}$ ) conditions respectively (Liu et al., 2019).

Uncertainty in $\kappa$ is due in part to measurement uncertainty of the HTDMA system and uncertainty resulting from nonideality effects in the solution droplets, surface tension reduction due to surface-active substances, and the presence of slightly soluble substances that dissolve at a RH higher than that maintained in the HTDMA (e.g., Wex et al., 2009; Good et al., 2010; Irwin et al., 2010; Cerully et al., 2011; Wu et al., 2013). For example, the HTDMA may overestimate the $D_{\mathrm{p}}$ of dry particles for the external mixed $\mathrm{BC}$ particles, as BCcontaining particles may shrink when humidified, leading to an underestimate of the hygroscopic growth factor. However, our previous study demonstrated that, for this region, estimates using HTDMA data are still better representing the aerosol hygroscopicity than those using the simple mixing rule based on chemical volume fractions for an assumed internal mixture (Zhang et al., 2017). Therefore, here we focus on discussing and exploring the uncertainty of $\kappa_{\text {chem }}$ by taking $\kappa_{\mathrm{gf}}$ as the reference.

The results show that, although the slopes from linear fitting of $\kappa_{\text {chem }}$ and $\kappa_{\mathrm{gf}}$ are close to 1.0, it shows correlations that are quite poor (typically with correlation coefficients, $R^{2}$, of $<0.3$ ) between $\kappa_{\text {chem }}$ and $\kappa_{\text {gf }}$ of the 80, 110, 150, and $200 \mathrm{~nm}$ particles in both winter and summer. The poor correlations reflect large uncertainty in one or both of the calculated parameters that are likely due to the unreasonable assumption of particle mixing state (e.g., Cruz and Pandis, 2000; Svenningsson et al., 2006; Sjogren et al., 2007; Zardini et al., 2008), which varies with their aging and other physiochemical processes in the atmosphere. Note that underestimation of $\kappa_{\text {chem }}$ for the summer occurred mostly in the afternoon (shown in blue dots in Fig. 5). This may be associated with photochemical processes at around noontime. More specific investigations of the particle mixing and aging 
(a)

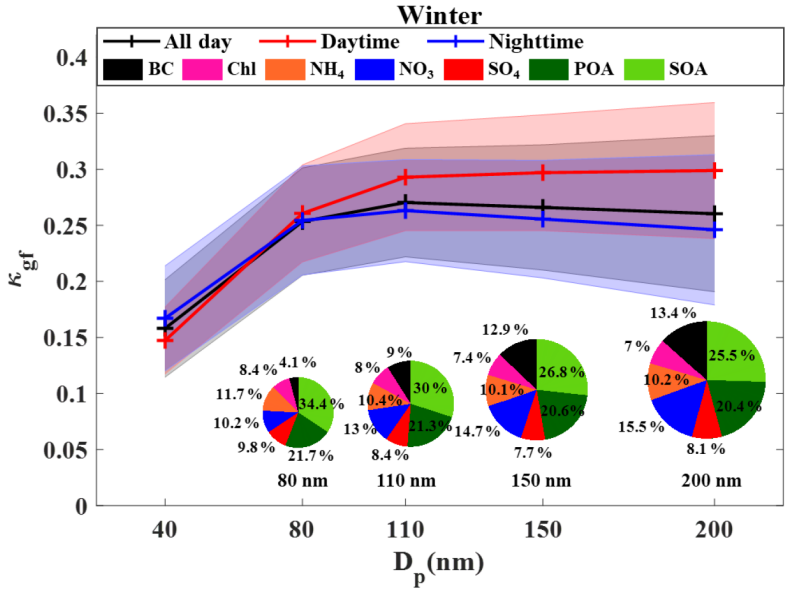

(b)

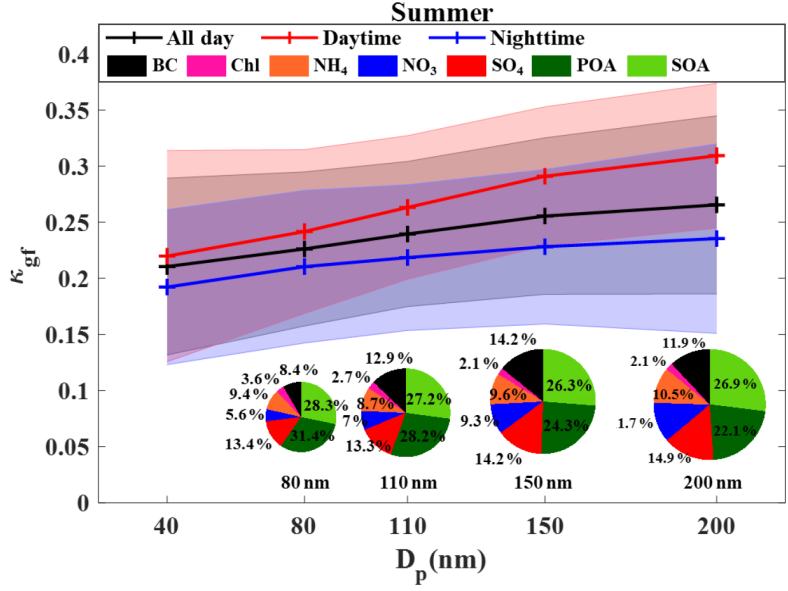

Figure 4. The dependence of $\kappa$ on $D_{\mathrm{p}}$ at the urban Beijing site during winter (a) and summer (b). The $\kappa$ values are retrieved from the size-resolved HTDMA measurements. The error bars represent $\pm 1 \sigma$. The size-resolved chemical mass fraction at the corresponding $D_{\mathrm{p}}$ is also presented.

impacts on $\kappa_{\text {chem }}$ will be further addressed in the following sections.

\subsection{Aerosols aging and source effects indicated by diurnal cycles of $\kappa_{\text {chem }}$ and $\kappa_{\mathrm{gf}}$}

The diurnal cycles of particle hygroscopicity in the summer and winter with the use of the size-resolved chemical composition observations and the ratio of $\kappa_{\text {chem }}$ to $\kappa_{\text {gf }}$ are shown in Fig. 6. In summer, at 09:00-15:00, the disparity between $\kappa_{\text {chem }}$ and $\kappa_{\mathrm{gf}}$ is insignificant for smaller particles (80 and $110 \mathrm{~nm}$ ), and both of them show a slight decrease from 09:00 or 10:00 to $12: 00-13: 00$ due to the frequent NPF event that usually corresponds to a large fraction of organics (Fig. 3) in urban Beijing. For larger particles (150 and $200 \mathrm{~nm}$ ), the disparity between $\kappa_{\text {chem }}$ and $\kappa_{\mathrm{gf}}$ around noontime and in the early afternoon is very significant, corresponding to $>20 \%$ underestimation of particle hygroscopicity by $\kappa_{\text {chem }}$ (with a ratio of $\kappa_{\text {chem }}$ to $\kappa_{\mathrm{gf}}$ of $\left.\sim 0.8\right)$. Similar patterns were also
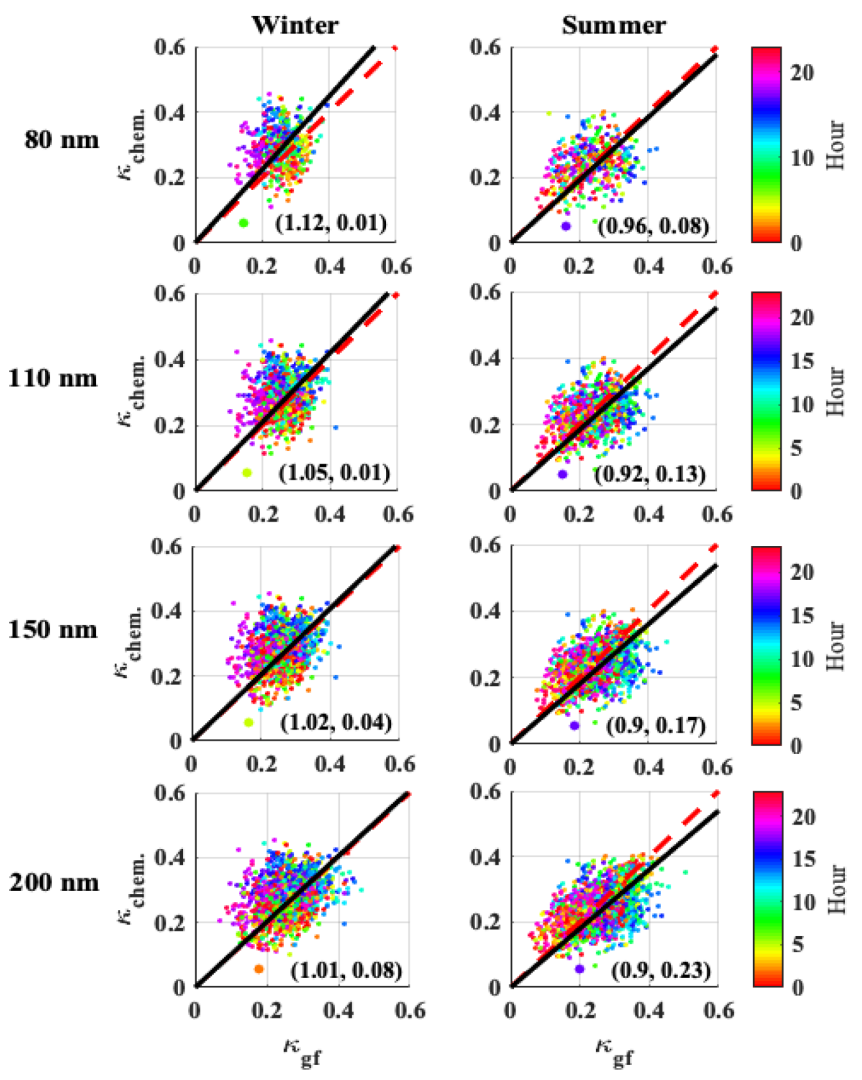

Figure 5. Closure of $\kappa_{\text {chem }}$ calculated from size-resolved chemical composition data and $\kappa_{\mathrm{gf}}$ retrieved from the hygroscopic growth factor by HTDMA measurements in the winter (left panels) and summer (right panels) period. The dots with different colors correspond to the observed time of a day during the campaign as shown by the color bar. In each plot, the red dotted line is the $1: 1$ line, and the black solid line is the fitting line. The numbers in parentheses are slopes of linear fits and correlation coefficients $\left(R^{2}\right)$.

noted by Zhang et al. (2017) but only based on a comparison between $\kappa_{\text {chem }}$ derived from bulk chemical composition and $\kappa_{\text {gf }}$. Our results based on size-resolved measurements are consistent with that observed by Zhang et al. (2017), which again confirms the effect of the rapid photochemical aging of aerosol particles on their hygroscopicity. In contrast, no significant differences between $\kappa_{\mathrm{chem}}$ and $\kappa_{\mathrm{gf}}$ are observed during nighttime in summer. Note that $\kappa_{\text {chem }}$ is slightly higher than $\kappa_{\mathrm{gf}}$ during early evening traffic rush hour and cooking time, when emissions of primary hydrophobic particles (e.g., $\mathrm{BC}$ and POA) are high (Fig. 3), thus resulting in a large percentage of externally mixed particles. Causes of the overestimation of $\kappa_{\text {chem }}$ during the traffic rush hour and cooking time will be discussed in the following paragraph. The particles experience rapid conversion and mixing in urban Beijing due to high precursor gases (Sun et al., 2015; Wu et al., 2016; Ren et al., 2018); thus, the aged particles produced through photochemical processes in the afternoon can mix and interact with the freshly emitted primary particles from traffic and 
(a)
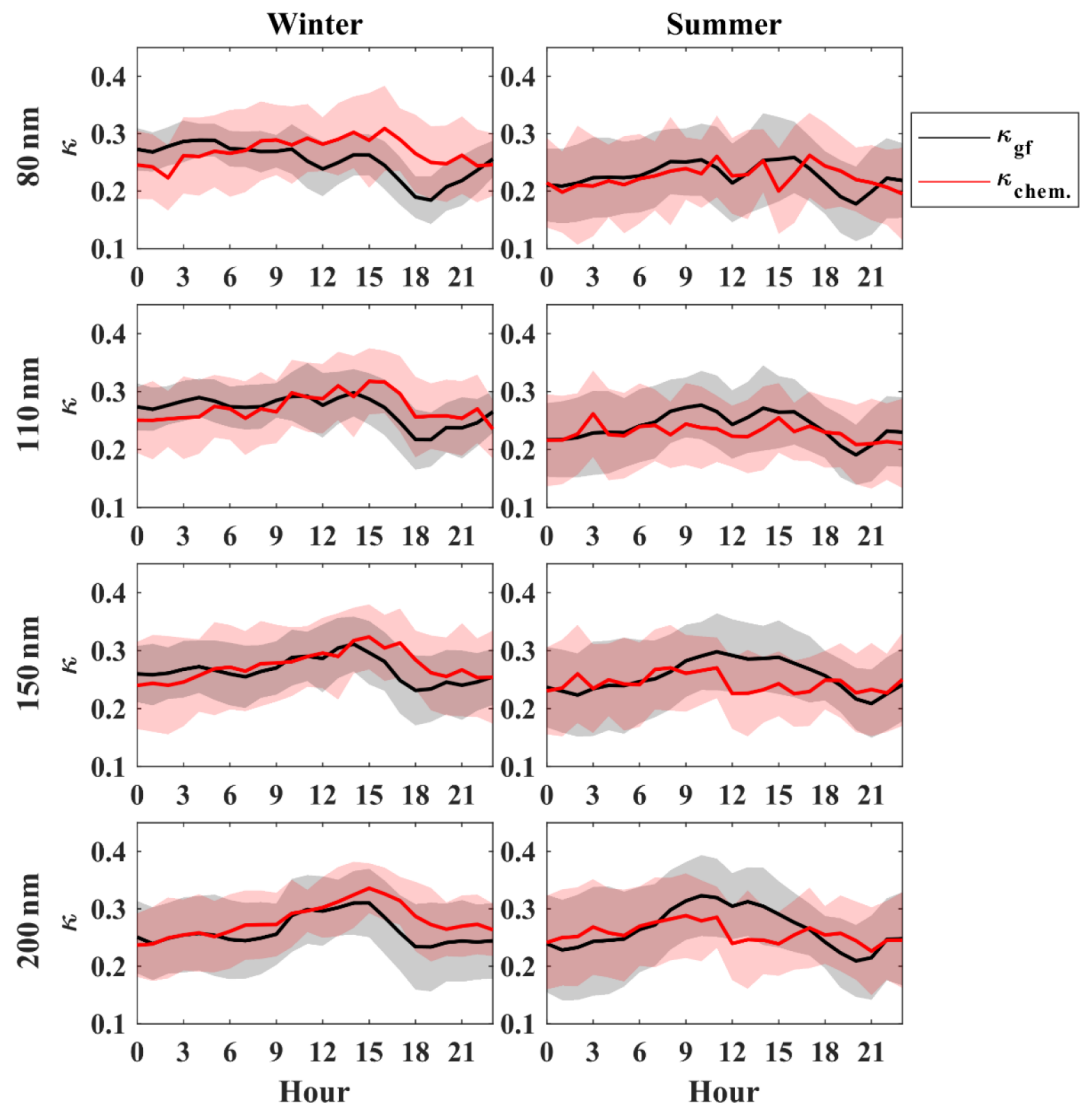

(b)
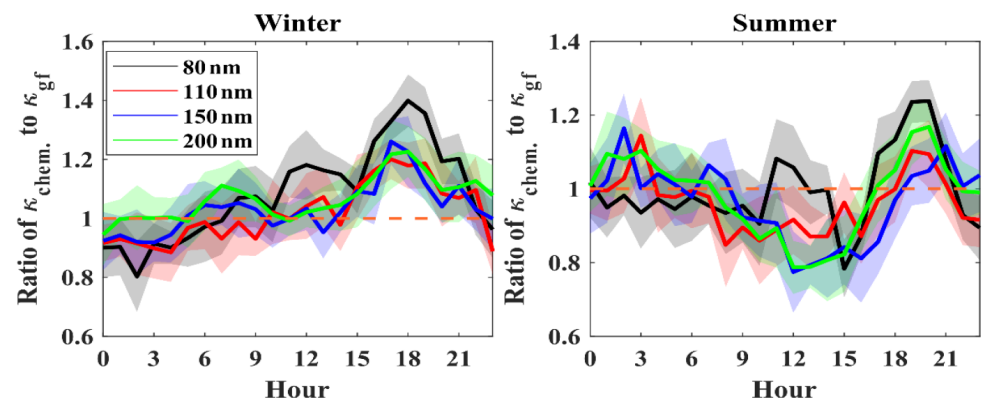

Figure 6. Diurnal variations of (a) $\kappa_{\text {chem }}$ using size-resolved chemical composition data and $\kappa_{\mathrm{gf}}$ in the winter and summer period and (b) the ratio of $\kappa_{\text {chem }}$ to $\kappa_{\mathrm{gf}}$ in the winter and summer period. The shade regions denote the error bars $(1 \sigma)$.

cooking sources (Wu et al., 2008). Therefore, during nighttime (22:00-06:00 LT), the particles are more uniform and internally mixed, which is reflective of the assumption for the calculation of $\kappa_{\text {chem }}$; a much better consistency between $\kappa_{\text {chem }}$ and $\kappa_{\mathrm{gf}}$ is hence presented.

In winter, the disparity between $\kappa_{\text {chem }}$ and $\kappa_{\text {gf }}$ is insignificant at 09:00-15:00 due to the weakening effect of photochemical aging. From 15:00 to 21:00 LT, due to the strong vehicle and cooking sources around the site, the particles are dominated by the hydrophobic mode with a large concentration of externally mixed BC and POA particles (Fig. 3); the calculated $\kappa_{\text {chem }}$ is much higher than $\kappa_{\mathrm{gf}}$, with a maximum ratio of $\kappa_{\text {chem }}$ to $\kappa_{\mathrm{gf}}$ of 1.4 ; and the greatest disparity is observed for small particles. The disparity is further enhanced during clean periods when the hydrophobic mode is dominant (Figs. 7, S1 in the Supplement). Note that during the nighttime, $\kappa_{\text {chem }}$ is slight lower than $\kappa_{\text {gf }}$, with a minimum ratio of $\kappa_{\text {chem }}$ to $\kappa_{\mathrm{gf}}$ of $\sim 0.8$ for $80 \mathrm{~nm}$ particles and $\sim 0.9$ for 110 and $150 \mathrm{~nm}$ particles at 02:00-04:00 LT (Fig. 6b), indicating an underestimation of particle hygroscopicity using composition data. The disparity at nighttime is further increased during heavily polluted events (Fig. S1), when the particles are more internally mixed with only one hygroscopic mode (Fig. 7). We propose the increased underestimation during polluted conditions is likely due to enhanced condensation of secondary hygroscopic compounds (e.g., ni- 


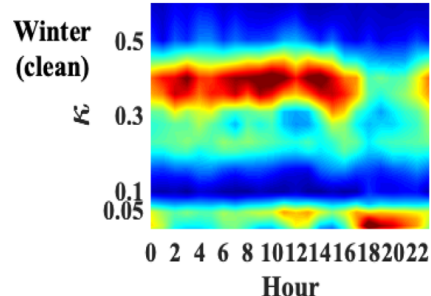

Hour

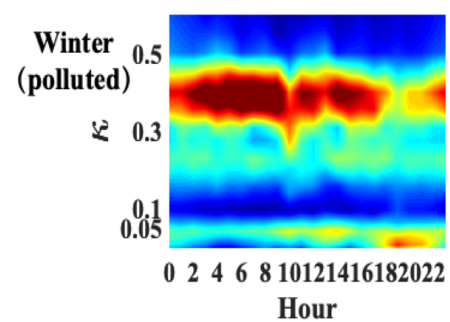

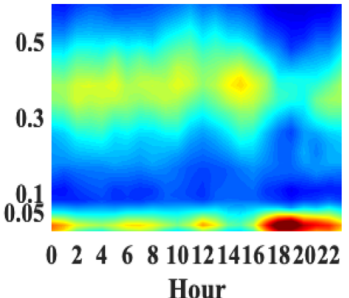

Hour

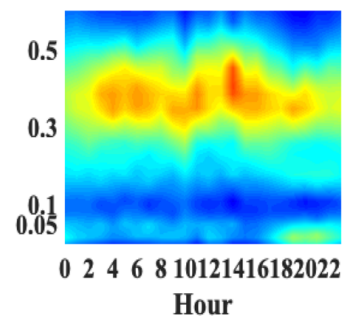

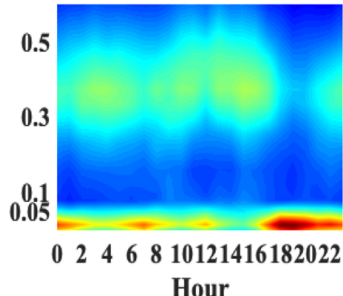

Hour

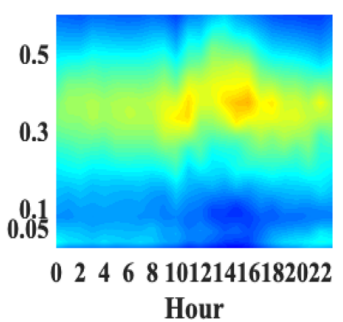

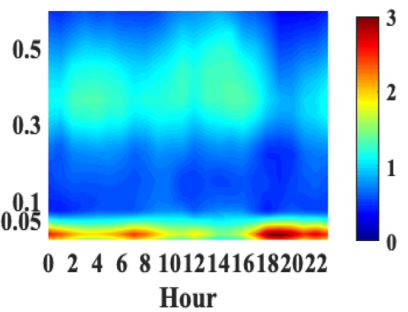

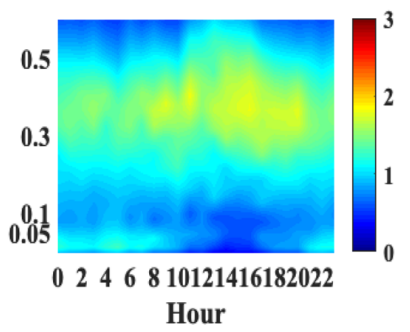

Figure 7. Diurnal cycles of $\kappa_{\text {gf }}$ PDF for $80,110,150$, and $200 \mathrm{~nm}$ particles in clean and polluted events in winter.

trate, sulfate, SOA) on preexisting aerosols at lower temperature and or hydrophilic SOA formation under higher relative humidity at nighttime (Wu et al., 2008; Wang et al., 2016; An et al., 2019). However, such a condensation effect during nighttime is less significant (indicated by the smaller disparity between $\kappa_{\text {chem }}$ and $\kappa_{\mathrm{gf}}$ ) than the aging effect caused by aerosol photochemical processes around noontime (J. F. Peng et al., 2016).

We suppose that the higher/lower $\kappa_{\text {chem }}$ should first be closely associated with temporal changes in actual effective density of $\mathrm{BC}$ with the particles aging/diurnal variations of local emissions. It has been demonstrated that rapid aging of $\mathrm{BC}$ can occur over a few hours in the polluted urban area (J. F. Peng et al., 2016). The externally mixed BC particles have a fractal structure and chain-like aggregates and have been reported with an effective density of $0.25-0.45 \mathrm{~g} \mathrm{~cm}^{-3}$ (McMurry et al., 2002), while the BC particles in the $\kappa_{\text {chem }}$ calculation are assumed to be void-free with an effective density of $1.7 \mathrm{~g} \mathrm{~cm}^{-3}$. This leads to a lower BC volume fraction than it actually is and thus a greater $\kappa_{\text {chem }}$ during the traffic rush hour and cooking time when $\mathrm{BC}$ particles are mostly freshly emitted with uncompacted structure. In addition, the significant increase in volume fraction of POA during the late afternoon would result in changes in composition of organic aerosols, and thereby a density much closer to that of POA than the assumed one $\left(1.2 \mathrm{~g} \mathrm{~cm}^{-3}\right)$ in the calculation should be applied. A sensitivity test has been done to examine the effect of density of BC and organics on the calculated $\kappa_{\text {chem }}$ (Fig. 8). The result shows that the $\kappa_{\text {chem }}$ value can be reduced by $16 \%-33 \%$ by decreasing the $\mathrm{BC}$ effective density from 1.7 to $0.25-0.45 \mathrm{~g} \mathrm{~cm}^{-3}$. This basically explains the disparity between $\kappa_{\text {chem }}$ and $\kappa_{\mathrm{gf}}$ during the traffic rush hour when a large amount of $\mathrm{BC}$ is freshly emitted. The changes in $\kappa_{\text {chem }}$ are within $\pm 4 \%$ by varying the organic density from 1.2 (mixture of SOA and POA) to 1.0 (typically for POA) or
$1.4 \mathrm{~g} \mathrm{~cm}^{-3}$ (typically for SOA) (Zamora et al., 2019), showing a much lower impact of variations of organic density on $\kappa_{\text {chem. }}$. In conclusion, the result demonstrated that the disparity between $\kappa_{\text {chem }}$ and $\kappa_{\mathrm{gf}}$ during the late afternoon in winter is largely due to the inappropriate use of the $\mathrm{BC}$ particle density that is closely associated with its morphology or the degree of its aging. Our study suggests that, to accurately parameterize the effect of $\mathrm{BC}$ aging on particle hygroscopicity, it is critical to measure the effective density and morphology of ambient $\mathrm{BC}$, in particular in those regions with complex influences of rapid secondary conversion/aging processes and local sources.

In that way, the lower $\kappa_{\text {chem }}$ value derived around noontime in summer, when $\mathrm{BC}$ aerosols may be more compact through strong photochemical aging, is probably due to application of a lower BC density in the calculation. However, the sensitivity test indicates that, to fill the gap between $\kappa_{\text {chem }}$ and $\kappa_{\mathrm{gf}}$ observed at noontime in summer, the effective density of $\mathrm{BC}$ should be extremely high due to decreased sensitivity of $\kappa_{\text {chem }}$ to BC density with its aging. In this case, the density of $\mathrm{BC}$ has been assumed to be $1.7 \mathrm{~g} \mathrm{~cm}^{-3}$, which reflects a very compacted and void-free structure of the $\mathrm{BC}$ particles. This currently applied value represents an upper limit for the effective density of ambient BC particles according to previous observations near or in Beijing (Zhang et al., 2015), which suggested the aged BC generally has an effective density of $1.2-1.4 \mathrm{~g} \mathrm{~cm}^{-3}$. Using these ambient observed values would lead to further underestimation of $\kappa_{\mathrm{chem}}$. In addition, the photochemical aging can change the overall effective density of organic aerosols by changing their chemical composition. However, the effective density of the photochemical oxidized organic particles (e.g., SOA) does not change much on the timescale of several hours and was observed ranging between 1.2 and $1.3 \mathrm{~g} \mathrm{~cm}^{-3}$ (Bahreini et al., 2005). It can only explain $\sim 4 \%$ at most of the underesti- 
(a)

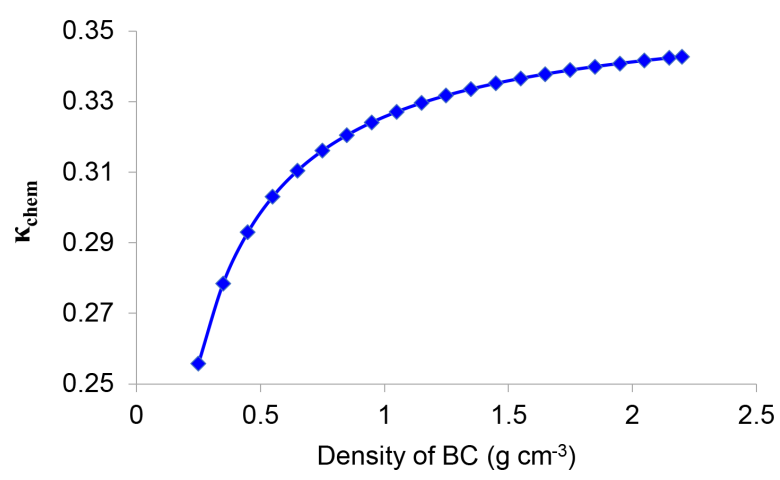

(b)

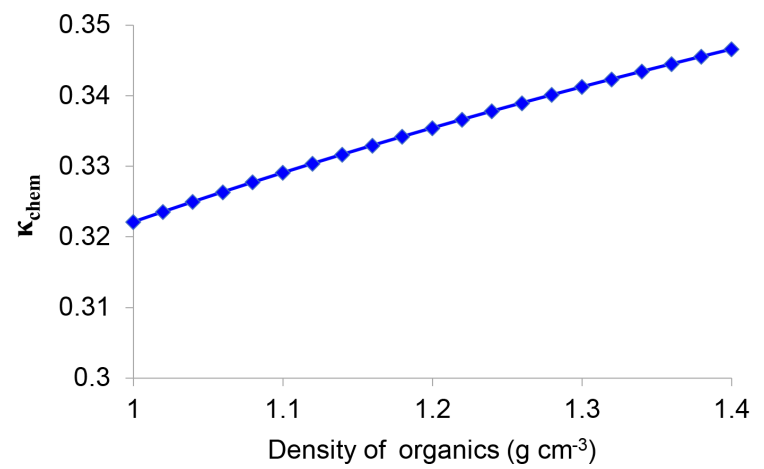

Figure 8. Sensitivity of $\kappa_{\text {chem }}$ to variations in the density of BC (a) and organics (b).

mation in $\kappa_{\text {chem }}$ around noontime in summer by applying a density value of $1.4 \mathrm{~g} \mathrm{~cm}^{-3}$ (typically for SOA). Therefore, the application of higher densities of $\mathrm{BC}$ and organics in the calculation cannot fully explain the disparity between $\kappa_{\text {chem }}$ and $\kappa_{\mathrm{gf}}$ during the early afternoon in summer when strong photochemical processes are expected.

The uncertainty in the calculation of $\kappa_{\text {chem }}$ may be also related to the uncertainty caused by the hygroscopic parameter of organics that vary widely over a range of diverse constituents of SOA (Suda et al., 2012). The lower $\kappa_{\text {chem }}$ indicates that the $\kappa$ of secondary organic aerosols formed through the strong photochemical oxidation processes in summer of urban Beijing is likely underestimated. In this study, the mean $\kappa$ value of organics derived from the $f_{44}$ parameterized equation is $0.20 \pm 0.02$, ranging from 0.17 to 0.23 during 09:00-17:00. While the organic aerosols, especially for particles in accumulated mode, may be more hygrophilic with a much larger $\kappa$, i.e., $>0.2$ due to large formation of highly oxidized OA. One can easily understand that increasing the $\kappa$ of organic aerosols from 0.2 to 0.3 can explain about $11 \%-$ $13 \%$ of the underestimation of $\kappa_{\text {chem }}$, but this represents an upper limit of the impact of hygroscopicity of organic aerosols on the calculation. This is because the $\kappa$ value of 0.3 corresponds to the maximum possible for ambient organic aerosols. Additionally, the $f_{44}$ parameterized equation tends to overestimate the $\kappa$ according to Fröhlich et al. (2015), which should yield a larger $\kappa_{\text {chem }}$. Finally, the coexisting hygroscopic and hydrophobic species may have a strong influence on the phase state of particles, also likely affecting chemical interactions between inorganic and organic compounds as well as the overall hygroscopicity of mixed particles (C. Peng et al., 2016). Overall, the lower $\kappa_{\text {chem }}$ caused by the photochemical aging effect likely resulted from multiple impacts of inappropriate application of the density and hygroscopic parameter of organic aerosols in the calculation, as well as the influences from chemical interaction between organic and inorganic compounds on the overall hygroscopicity of mixed particles. This topic warrants further investigations.

\subsection{Observation from other stations}

The aging process in the summer period is related to photochemical processing in strong solar radiation conditions. The photochemical reactions produce sulfate and secondary organic aerosol, condensing on the surface of slightly hygroscopic or nonhygroscopic primary aerosols (such as BC) (Zhang et al., 2008). To confirm such a photochemical aging effect on particle hygroscopicity, we further examine the diurnal variations of $\kappa_{\mathrm{chem}}$ and $\kappa_{\mathrm{gf}}$ or $\kappa_{\mathrm{CCNc}}$ (only at the XZ site) based on observations in summer at two other sites in north China (Fig. 1). The XT site is located in the suburbs of XT city, which is about $400 \mathrm{~km}$ south of Beijing, with high levels of industrialization and urbanization. Due to industrial emissions and typically weak ventilating winds, concentrations of $\mathrm{PM}_{2.5}$, black carbon, and gaseous precursors are usually high at the site (Fu et al., 2014). Xinzhou is located in the north of Taiyuan and about $360 \mathrm{~km}$ southwest of Beijing and is surrounded by mountains on three sides. Local emissions from motor vehicles and industrial activities have relatively little influence on the sampled aerosol (Zhang et al., 2016). Because of its location and elevation, the aerosol at the $\mathrm{XZ}$ site is usually aged and transported from other areas. The sampling period was from 22 July to 26 August 2014 and from 17 May to 14 June 2016 at the XZ and XT site respectively.

We find that the case at the XT site is very similar to that observed in BJ (Fig. 9a), with a lower $\kappa_{\text {chem }}$ than $\kappa_{\text {gf }}$ around noon time. But, because of much fewer influences from the local sources at XT compared to that at BJ, such underestimation by $\kappa_{\text {chem }}$ continued until night at XT (Fig. 9b). Interestingly, a noontime lower $\kappa_{\text {chem }}$ was not observed in the diurnal cycles at the $\mathrm{XZ}$ site, where $\kappa_{\text {chem }}$ and $\kappa_{\mathrm{CCNc}}$ had similar diurnal patterns (Fig. 9c) with a roughly constant ratio of $\kappa_{\text {chem }}$ to $\kappa_{\mathrm{CCNc}}$ of $\sim 0.8-0.9$ (Fig. 9d). This is probably because the $\mathrm{XZ}$ site is usually the recipient of aerosols transported from other areas that are already aged and well-mixed, with minimal impact of further aging (Zhang et al., 2017). Also, the rate of oxidation and condensation may be slow in the relatively remote area where the gas precursors and oxidants are not as high as they are closer to source regions. 
(a)

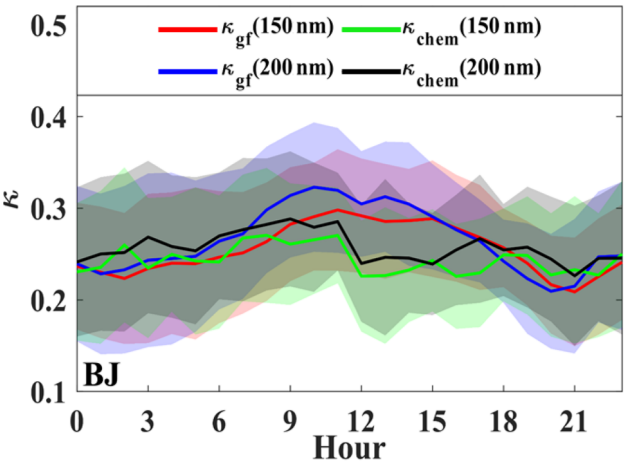

(c)

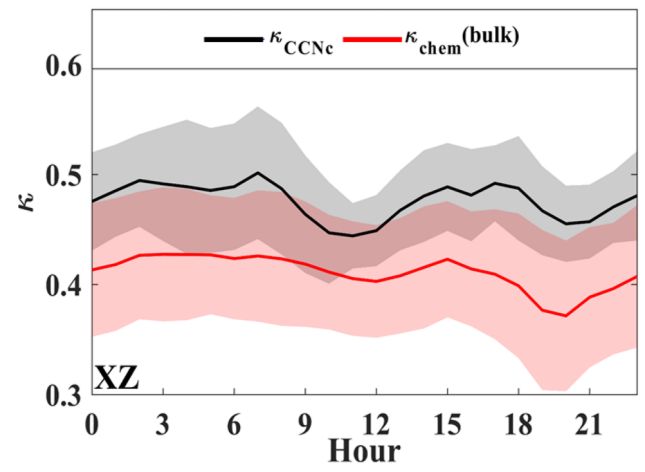

(b)
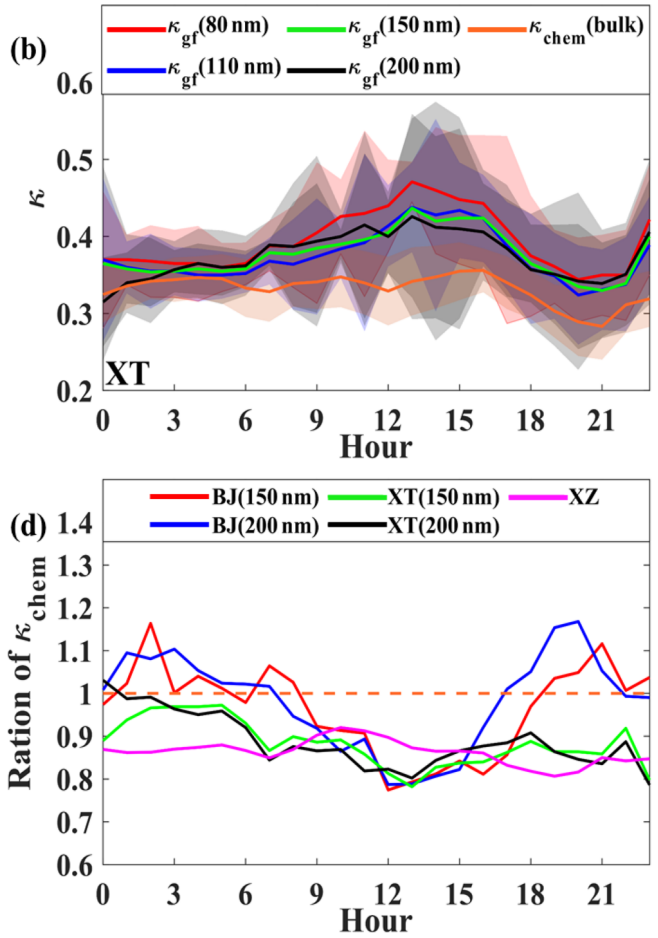

Figure 9. Diurnal variations in (a) $\kappa_{\mathrm{chem}}$ and $\kappa_{\mathrm{gf}}$ for 150 and $200 \mathrm{~nm}$ particles at the BJ site; (b) $\kappa_{\mathrm{chem}}$ and $\kappa_{\mathrm{gf}}$ for $40,80,110,150$, and $200 \mathrm{~nm}$ particles at the XT site; (c) $\kappa_{\mathrm{chem}}$ and mean $\kappa_{\mathrm{CCNc}}$ for particles at the XZ site; and (d) ratio of mean $\kappa_{\mathrm{chem}}$ to $\kappa_{\mathrm{gf}}$ at the three sites.

But at XT, which is located in the heavily polluted area in the North China Plain (Fu et al., 2014), aerosol emissions and processing are more similar to that in urban Beijing. These observations from other sites further confirm the photochemical aging effect that will largely underestimate the particle hygroscopicity using a simple mixing rule based on chemical composition.

\section{Conclusions}

Using measurements of aerosol composition and hygroscopicity made in Beijing (BJ) during a winter period of 2016 and a summer period of 2017, this paper analyzes the daily variation and seasonal differences of size-resolved aerosol hygroscopicity in urban Beijing. We mainly focus on studying the disparity of $\kappa_{\mathrm{gf}}$ and $\kappa_{\mathrm{chem}}$ between summer and winter to reveal the impact of atmospheric processes and mixing state of the particles on its hygroscopicity. The uncertainty in calculating $\kappa$ by using chemical composition with a uniform internal mixing hypothesis is elucidated from the diurnal variations of the difference between the calculated values: in summer, a lower $\kappa_{\text {chem }}$ is obtained around noontime, with a ratio of $\kappa_{\text {chem }}$ to $\kappa_{\mathrm{gf}}$ of about $0.8-0.9$ for large particles (i.e., 150 and $200 \mathrm{~nm}$ ), showing an underestimation of particle hygroscopicity by using a simple mixing rule based on chemical composition. Combining with the observation from $\mathrm{XT}$ and $\mathrm{XZ}$, we attribute the underestimation to the rapid noontime photochemical aging processes in summer, which induces the aging effect that will lead to a lower $\kappa$ if assuming a uniform mixing of the particles. The lower $\kappa_{\text {chem }}$ likely resulted from multiple impacts of inappropriate application of the density and hygroscopic parameter of organic aerosols in the calculation, as well as the unknown influences from chemical interaction between organic and inorganic compounds on the overall hygroscopicity of mixed particles.

In winter, a larger $\kappa_{\text {chem }}$ than $\kappa_{\mathrm{gf}}$ for $>100 \mathrm{~nm}$ particles is derived around noontime and in the early afternoon, with a maximum ratio of $\kappa_{\text {chem }}$ to $\kappa_{\mathrm{gf}}$ of 1.2-1.4 when the particles are dominated by the hydrophobic mode with a large number of externally mixed POA particles from strong vehicle and cooking sources. We attribute this large disparity between $\kappa_{\text {chem }}$ and $\kappa_{\mathrm{gf}}$ to changes in $\mathrm{BC}$ morphology that can be indicated by the effective density of BC. The sensitivity test shows that it can well explain the disparity during the traffic rush hour by applying a BC effective density of $0.25-0.45 \mathrm{~g} \mathrm{~cm}^{-3}$. However, we suggest that, to accurately parameterize or account for the effect of BC density on particle hygroscopicity, future investigations need to measure the effective density of ambient $\mathrm{BC}$, in particular in those regions with complex local sources. Our results highlight the impacts of atmospheric processes and sources on aerosol mixing state and hygroscopicity, which should be quantified and considered in models for different atmospheric conditions. 
Data availability. All data used in the study are available on http://www.geodoi.ac.cn/WebEn/doi.aspx? $\mathrm{Id}=1356$ (https://doi.org/10.3974/geodb.2019.06.11.V1, Fan et al., 2019) or from the corresponding author upon request (fang.zhang@bnu.edu.cn).

Supplement. The supplement related to this article is available online at: https://doi.org/10.5194/acp-20-915-2020-supplement.

Author contributions. FZ and JL conceived the conceptual development of the paper. XF directed and performed the experiments with LC, XJ, YW, and FZ. FZ, JL, and XF conducted the data analysis and wrote the draft of the paper, and all authors edited and commented on the various sections of the paper. JL and XF contributed equally to this work.

Competing interests. The authors declare that they have no conflict of interest.

Special issue statement. This article is part of the special issue "In-depth study of air pollution sources and processes within Beijing and its surrounding region (APHH-Beijing) (ACP/AMT interjournal SI)". It is not associated with a conference.

Acknowledgements. We thank all participants of the field campaign for their tireless work and cooperation. We also would like to thank the two anonymous reviewers for their insightful and constructive comments.

Financial support. This research has been supported by the National Natural Science Foundation of China (NSFC) research projects (grant nos. 41975174 and 41675141 ) and the National Key R\&D Program of China (grant no. 2017YFC1501702).

Review statement. This paper was edited by James Allan and reviewed by two anonymous referees.

\section{References}

An, Z., Huang, R. J., Zhang, R., Tie, X., Li, G., Cao, J., Zhou, W., Shi, Z., Han, Y., Gu, Z., and Ji, Y.: Severe haze in Northern China: A synergy of anthropogenic emissions and atmospheric processes, P. Natl. Acad. Sci. USA, 116, 8657-8666, https://doi.org/10.1073/pnas.1900125116, 2019.

Bahreini, R., Keywood, M. D., Ng, N. L., Varutbangkul, V., and Jimenez, J. L.: Measurements of secondary organic aerosol from oxidation of cycloalkenes, terpenes, and $m$-xylene using an aerodyne aerosol mass spectrometer, Environ. Sci. Technol., 39, 5674-5688, 2005.
Bougiatioti, A., Fountoukis, C., Kalivitis, N., Pandis, S. N., Nenes, A., and Mihalopoulos, N.: Cloud condensation nuclei measurements in the marine boundary layer of the Eastern Mediterranean: CCN closure and droplet growth kinetics, Atmos. Chem. Phys., 9, 7053-7066, https://doi.org/10.5194/acp-9-7053-2009, 2009.

Carrico, C. M., Petters, M. D., Kreidenweis, S. M., Collett Jr., J. L., Engling, G., and Malm, W. C.: Aerosol hygroscopicity and cloud droplet activation of extracts of filters from biomass burning experiments, J. Geophys. Res., 113, D08206, https://doi.org/10.1029/2007JD009274, 2008.

Cerully, K. M., Raatikainen, T., Lance, S., Tkacik, D., Tiitta, P., Petäjä, T., Ehn, M., Kulmala, M., Worsnop, D. R., Laaksonen, A., Smith, J. N., and Nenes, A.: Aerosol hygroscopicity and CCN activation kinetics in a boreal forest environment during the 2007 EUCAARI campaign, Atmos. Chem. Phys., 11, 12369-12386, https://doi.org/10.5194/acp-11-12369-2011, 2011.

Chang, R.-W., Liu, P., Leaitch, W., and Abbatt, J.: Comparison between measured and predicted $\mathrm{CCN}$ concentrations at Egbert, Ontario: Focus on the organic aerosol fraction at a semi-rural site, Atmos. Environ., 41, 8172-8182, 2007.

Collins, D. R., Flagan, R. C., and Seinfeld, J. H.: Improved inversion of scanning DMA data, Aerosol Sci. Tech., 36, 1-9, 2002.

Cruz, C. N. and Pandis, S. N.: Deliquescence and hygroscopic growth of mixed inorganic-organic atmospheric aerosol, Environ. Sci. Technol., 34, 4313-4319, https://doi.org/10.1021/es9907109, 2000.

Fan, X., Liu, J., Zhang, F., Chen, L., Collins, D., Xu, W., Jin, X., Ren, J., Wang, Y., Wu, H., Li, S., Sun, Y., and Li, Z.: HTDMA and HR-ToF-AMS Measured in situ Dataset in Winter of 2016 and Summer of 2017 at the Beijing Observation Station[DB/OL], Global Change Research Data Publishing \& Repository, https://doi.org/10.3974/geodb.2019.06.11.V1, 2019.

Fröhlich, R., Crenn, V., Setyan, A., Belis, C. A., Canonaco, F., Favez, O., Riffault, V., Slowik, J. G., Aas, W., Aijälä, M., Alastuey, A., Artiñano, B., Bonnaire, N., Bozzetti, C., Bressi, M., Carbone, C., Coz, E., Croteau, P. L., Cubison, M. J., EsserGietl, J. K., Green, D. C., Gros, V., Heikkinen, L., Herrmann, H., Jayne, J. T., Lunder, C. R., Minguillón, M. C., Močnik, G., O’Dowd, C. D., Ovadnevaite, J., Petralia, E., Poulain, L., Priestman, M., Ripoll, A., Sarda-Estève, R., Wiedensohler, A., Baltensperger, U., Sciare, J., and Prévôt, A. S. H.: ACTRIS ACSM intercomparison - Part 2: Intercomparison of ME-2 organic source apportionment results from 15 individual, co-located aerosol mass spectrometers, Atmos. Meas. Tech., 8, 2555-2576, https://doi.org/10.5194/amt-8-2555-2015, 2015.

Fu, G. Q., Xu, W. Y., Yang, R. F., Li, J. B., and Zhao, C. S.: The distribution and trends of fog and haze in the North China Plain over the past 30 years, Atmos. Chem. Phys., 14, 11949-11958, https://doi.org/10.5194/acp-14-11949-2014, 2014.

Good, N., Topping, D. O., Allan, J. D., Flynn, M., Fuentes, E., Irwin, M., Williams, P. I., Coe, H., and McFiggans, G.: Consistency between parameterisations of aerosol hygroscopicity and CCN activity during the RHaMBLe discovery cruise, Atmos. Chem. Phys., 10, 3189-3203, https://doi.org/10.5194/acp10-3189-2010, 2010.

Gunthe, S. S., King, S. M., Rose, D., Chen, Q., Roldin, P., Farmer, D. K., Jimenez, J. L., Artaxo, P., Andreae, M. O., Martin, S. T., and Pöschl, U.: Cloud condensation nuclei in pristine tropi- 
cal rainforest air of Amazonia: size-resolved measurements and modeling of atmospheric aerosol composition and CCN activity, Atmos. Chem. Phys., 9, 7551-7575, https://doi.org/10.5194/acp9-7551-2009, 2009.

Gysel, M., McFiggans, G. B., and Coe, H.: Inversion of tandem differential mobility analyser (TDMA) measurements, J. Aerosol Sci., 40, 134-151, https://doi.org/10.1016/j.jaerosci.2008.07.013, 2009.

Hu, W., Hu, M., Hu, W., Jimenez, J. L., Yuan, B., Chen, W., Wang, M., Wu, Y., Chen, C., Wang, Z., Peng, J., Zeng, L., and Shao, M.: Chemical composition, sources, and aging process of submicron aerosols in Beijing: Contrast between summer and winter, J. Geophys. Res., 121, 1955-1977, https://doi.org/10.1002/2015JD024020, 2016.

Irwin, M., Good, N., Crosier, J., Choularton, T. W., and McFiggans, G.: Reconciliation of measurements of hygroscopic growth and critical supersaturation of aerosol particles in central Germany, Atmos. Chem. Phys., 10, 11737-11752, https://doi.org/10.5194/acp-10-11737-2010, 2010.

Kuwata, M., Kondo, Y., Miyazaki, Y., Komazaki, Y., Kim, J. H., Yum, S. S., Tanimoto, H., and Matsueda, H.: Cloud condensation nuclei activity at Jeju Island, Korea in spring 2005, Atmos. Chem. Phys., 8, 2933-2948, https://doi.org/10.5194/acp-8-29332008, 2008.

Liu, D., Joshi, R., Wang, J., Yu, C., Allan, J. D., Coe, H., Flynn, M. J., Xie, C., Lee, J., Squires, F., Kotthaus, S., Grimmond, S., Ge, X., Sun, Y., and Fu, P.: Contrasting physical properties of black carbon in urban Beijing between winter and summer, Atmos. Chem. Phys., 19, 6749-6769, https://doi.org/10.5194/acp19-6749-2019, 2019.

Liu, P. F., Zhao, C. S., Göbel, T., Hallbauer, E., Nowak, A., Ran, L., Xu, W. Y., Deng, Z. Z., Ma, N., Mildenberger, K., Henning, S., Stratmann, F., and Wiedensohler, A.: Hygroscopic properties of aerosol particles at high relative humidity and their diurnal variations in the North China Plain, Atmos. Chem. Phys., 11, 3479-3494, https://doi.org/10.5194/acp-11-3479-2011, 2011.

Massling, A., Stock, M., and Wiedensohler, A.: Diurnal, weekly, and seasonal variation of hygroscopic properties of submicrometer urban aerosol particles, Atmos. Environ., 39, 3911-3922, https://doi.org/10.1016/j.atmosenv.2005.03.020, 2005.

McMurry, P. H., Wang, X., Park, K., and Ehara, K.: The Relationship between Mass and Mobility for Atmospheric Particles, Aerosol Sci. Tech., 36, 227-238, 2002.

Mei, F., Hayes, P. L., Ortega, A. M., Taylor, J. W., Allan, J. D., Gilman, J. B., Kuster, W. C., de Gouw, J. A., Jimenez, J. L., and Wang, J.: Droplet activation properties of organic aerosols observed at an urban site during CalNex-LA, J. Geophys. Res., 118, 2903-2917, https://doi.org/10.1002/jgrd.50285, 2013.

Peng, C., Jing, B., Guo, Y. C., Zhang, Y. H., and Ge, M. F.: Hygroscopic behavior of multicomponent aerosols involving nacl and dicarboxylic acids, J. Phys. Chem. A, 120, 1029-1038, 2016.

Peng, J., Hu, M., Guo, S., Du, Z., Shang, D., Zheng, J., Zheng, J., Zeng, L., Shao, M., Wu, Y., Collins, D., and Zhang, R.: Ageing and hygroscopicity variation of black carbon particles in Beijing measured by a quasi-atmospheric aerosol evolution study (QUALITY) chamber, Atmos. Chem. Phys., 17, 10333-10348, https://doi.org/10.5194/acp-17-10333-2017, 2017a.

Peng, J., Hu, M., Du, Z., Wang, Y., Zheng, J., Zhang, W., Yang, Y., Qin, Y., Zheng, R., Xiao, Y., Wu, Y., Lu, S., Wu, Z., Guo,
S., Mao, H., and Shuai, S.: Gasoline aromatics: a critical determinant of urban secondary organic aerosol formation, Atmos. Chem. Phys., 17, 10743-10752, https://doi.org/10.5194/acp-1710743-2017, 2017b.

Peng, J. F., Hu, M., Wang, Z. B., Huang, X. F., Kumar, P., Wu, Z. J., Guo, S., Yue, D. L., Shang, D. J., Zheng, Z., and He, L. Y.: Submicron aerosols at thirteen diversified sites in China: size distribution, new particle formation and corresponding contribution to cloud condensation nuclei production, Atmos. Chem. Phys., 14, 10249-10265, https://doi.org/10.5194/acp-14-102492014, 2014.

Peng, J. F., Hu, M., Guo, S., Du, Z. F., Zheng, J., Shang, D. J., Zamora, M. L., Zeng, L. M., Shao, M., Wu, Y. S., Zheng, J., Wang, Y., Glen, C. R., Collins, D. R., Molina, M. J., and Zhang, R. Y.: Markedly enhanced absorption and direct radiative forcing of black carbon under polluted urban environments, P. Natl. Acad. Sci. USA, 113, 4266-4271, https://doi.org/10.1073/pnas.1602310113, 2016.

Petters, M. D. and Kreidenweis, S. M.: A single parameter representation of hygroscopic growth and cloud condensation nucleus activity, Atmos. Chem. Phys., 7, 1961-1971, https://doi.org/10.5194/acp-7-1961-2007, 2007.

Ren, J., Zhang, F., Wang, Y., Collins, D., Fan, X., Jin, X., Xu, W., Sun, Y., Cribb, M., and Li, Z.: Using different assumptions of aerosol mixing state and chemical composition to predict $\mathrm{CCN}$ concentrations based on field measurements in urban Beijing, Atmos. Chem. Phys., 18, 6907-6921, https://doi.org/10.5194/acp18-6907-2018, 2018.

Rose, D., Nowak, A., Achtert, P., Wiedensohler, A., Hu, M., Shao, M., Zhang, Y., Andreae, M. O., and Pöschl, U.: Cloud condensation nuclei in polluted air and biomass burning smoke near the mega-city Guangzhou, China - Part 1: Size-resolved measurements and implications for the modeling of aerosol particle hygroscopicity and CCN activity, Atmos. Chem. Phys., 10, 33653383, https://doi.org/10.5194/acp-10-3365-2010, 2010.

Schill, S. R., Collins, D. B., Lee, C., Morris, H. S., Novak, G. A., and Prather, K. A.: The impact of aerosol particle mixing state on the hygroscopicity of sea spray aerosol, ACS Central Science, 1, 132-141, 2015.

Sjogren, S., Gysel, M., Weingartner, E., Baltensperger, U., Cubison, M. J., Coe, H., Zardini, A. A., Marcolli, C., Krieger, U. K., and Peter, T.: Hygroscopic growth and water uptake kinetics of two-phase aerosol particles consisting of ammonium sulfate, adipic and humic acid mixtures, J. Aerosol Sci., 38, 157-171, https://doi.org/10.1016/j.jaerosci.2006.11.005, 2007.

Stokes, R. H. and Robinson, R. A.: Interactions in aqueous nonelectrolyte solutions: I. Solute-solvent equilibria, J. Phys. Chem., 70, 2126-2130, 1966.

Suda, S. R., Petters, M. D., Matsunaga, A., Sullivan, R. C., Ziemann, P. J., and Kreidenweis, S. M.: Hygroscopicity frequency distributions of secondary organic aerosols, J. Geophys. Res., 11, D04207, https://doi.org/10.1029/2011JD016823, 2012.

Sun, Y. L., Wang, Z. F., Du, W., Zhang, Q., Wang, Q. Q., Fu, P. Q., Pan, X. L., Li, J., Jayne, J., and Worsnop, D. R.: Longterm real-time measurements of aerosol particle composition in Beijing, China: seasonal variations, meteorological effects, and source analysis, Atmos. Chem. Phys., 15, 10149-10165, https://doi.org/10.5194/acp-15-10149-2015, 2015. 
Sun, Y., Du, W., Fu, P., Wang, Q., Li, J., Ge, X., Zhang, Q., Zhu, C., Ren, L., Xu, W., Zhao, J., Han, T., Worsnop, D. R., and Wang, Z.: Primary and secondary aerosols in Beijing in winter: sources, variations and processes, Atmos. Chem. Phys., 16, 8309-8329, https://doi.org/10.5194/acp-16-8309-2016, 2016.

Svenningsson, B., Rissler, J., Swietlicki, E., Mircea, M., Bilde, M., Facchini, M. C., Decesari, S., Fuzzi, S., Zhou, J., Mønster, J., and Rosenørn, T.: Hygroscopic growth and critical supersaturations for mixed aerosol particles of inorganic and organic compounds of atmospheric relevance, Atmos. Chem. Phys., 6, 1937-1952, https://doi.org/10.5194/acp-6-1937-2006, 2006.

Tan, H., Xu, H., Wan, Q., Li, F., Deng, X., Chan, P. W., Xia, D., and Yin, Y.: Design and application of an unattended multifunctional H-TDMA system, J. Atmos. Ocean. Tech., 30, 1136-1148, https://doi.org/10.1175/JTECH-D-12-00129.1, 2013.

Wang, J., Cubison, M. J., Aiken, A. C., Jimenez, J. L., and Collins, D. R.: The importance of aerosol mixing state and size-resolved composition on $\mathrm{CCN}$ concentration and the variation of the importance with atmospheric aging of aerosols, Atmos. Chem. Phys., 10, 7267-7283, https://doi.org/10.5194/acp10-7267-2010, 2010.

Wang, J., Zhang, Q., Chen, M.-D., Collier, S., Zhou, S., Ge, X., Xu, J., Shi, J., Xie, C., Hu, J., Ge, S., Sun, Y., and Coe, H.: First chemical characterization of refractory black carbon aerosols and associated coatings over the Tibetan Plateau (4730 m a.s.1), Environ. Sci. Technol., 51, 14072, https://doi.org/10.1021/acs.est.7b03973, 2017.

Wang, Q., Zhao, J., Du, W., Ana, G., Wang, Z., Sun, L., Wang, Y., Zhang, F., Li, Z., Ye, X., and Sun, Y.: Characterization of submicron aerosols at a suburban site in central China, Atmos. Environ., 131, 115-123, https://doi.org/10.1016/j.atmosenv.2016.01.054, 2016.

Wang, S. C. and Flagan, R. C.: Scanning Electrical Mobility Spectrometer, Aerosol Sci. Tech., 13, 230-240, 1990.

Wang, Y., Zhang, F., Li, Z., Tan, H., Xu, H., Ren, J., Zhao, J., $\mathrm{Du}, \mathrm{W}$., and Sun, Y.: Enhanced hydrophobicity and volatility of submicron aerosols under severe emission control conditions in Beijing, Atmos. Chem. Phys., 17, 5239-5251, https://doi.org/10.5194/acp-17-5239-2017, 2017.

Wang, Y., Li, Z., Zhang, Y., Du, W., Zhang, F., Tan, H., Xu, H., Fan, T., Jin, X., Fan, X., Dong, Z., Wang, Q., and Sun, Y.: Characterization of aerosol hygroscopicity, mixing state, and $\mathrm{CCN}$ activity at a suburban site in the central North China Plain, Atmos. Chem. Phys., 18, 11739-11752, https://doi.org/10.5194/acp-18-117392018, 2018a.

Wang, Y., Wu, Z. Ma, N., Wu, Y., Zeng, L., Zhao, C., and Wiedensohler, A.: Statistical analysis and parameterization of the hygroscopic growth of the sub-micrometer urban background aerosol in Beijing, Atmos. Environ., 175, 184-191, https://doi.org/10.1016/j.atmosenv.2017.12.003, 2018b.

Wex, H., Petters, M. D., Carrico, C. M., Hallbauer, E., Massling, A., McMeeking, G. R., Poulain, L., Wu, Z., Kreidenweis, S. M., and Stratmann, F.: Towards closing the gap between hygroscopic growth and activation for secondary organic aerosol: Part $1-$ Evidence from measurements, Atmos. Chem. Phys., 9, 3987-3997, https://doi.org/10.5194/acp-9-3987-2009, 2009.

Wu, Z., Hu, M., Lin, P., Liu, S., Wehner, B., and Wiedensohler, A.: Particle number size distribution in the urban at- mosphere of Beijing, China, Atmos. Environ., 42, 7967-7980, https://doi.org/10.1016/j.atmosenv.2008.06.022, 2008.

Wu, Z. J., Poulain, L., Henning, S., Dieckmann, K., Birmili, W., Merkel, M., van Pinxteren, D., Spindler, G., Müller, K., Stratmann, F., Herrmann, H., and Wiedensohler, A.: Relating particle hygroscopicity and $\mathrm{CCN}$ activity to chemical composition during the HCCT-2010 field campaign, Atmos. Chem. Phys., 13, 79837996, https://doi.org/10.5194/acp-13-7983-2013, 2013.

Wu, Z. J., Zheng, J., Shang, D. J., Du, Z. F., Wu, Y. S., Zeng, L. M., Wiedensohler, A., and Hu, M.: Particle hygroscopicity and its link to chemical composition in the urban atmosphere of Beijing, China, during summertime, Atmos. Chem. Phys., 16, $1123-$ 1138, https://doi.org/10.5194/acp-16-1123-2016, 2016.

Xu, W. Q., Sun, Y. L., Chen, C., Du, W., Han, T. T., Wang, Q. Q., Fu, P. Q., Wang, Z. F., Zhao, X. J., Zhou, L. B., Ji, D. S., Wang, P. C., and Worsnop, D. R.: Aerosol composition, oxidation properties, and sources in Beijing: results from the 2014 Asia-Pacific Economic Cooperation summit study, Atmos. Chem. Phys., 15, 13681-13698, https://doi.org/10.5194/acp-1513681-2015, 2015.

Ye, X., Tang, C., Yin, Z., Chen, J., Ma, Z., Kong, L., Yang, X., Gao, W., and Geng, F.: Hygroscopic growth of urban aerosol particles during the 2009 Mirage-Shanghai Campaign, Atmos. Environ., 64, 263-269, https://doi.org/10.1016/j.atmosenv.2012.09.064, 2013.

Zamora, M. L., Peng, J., Hu, M., Guo, S., Marrero-Ortiz, W., Shang, D., Zheng, J., Du, Z., Wu, Z., and Zhang, R.: Wintertime aerosol properties in Beijing, Atmos. Chem. Phys., 19, 14329-14338, https://doi.org/10.5194/acp-19-14329-2019, 2019.

Zardini, A. A., Sjogren, S., Marcolli, C., Krieger, U. K., Gysel, M., Weingartner, E., Baltensperger, U., and Peter, T.: A combined particle trap/HTDMA hygroscopicity study of mixed inorganic/organic aerosol particles, Atmos. Chem. Phys., 8, 55895601, https://doi.org/10.5194/acp-8-5589-2008, 2008.

Zhang, F., Li, Y., Li, Z., Sun, L., Li, R., Zhao, C., Wang, P., Sun, Y., Liu, X., Li, J., Li, P., Ren, G., and Fan, T.: Aerosol hygroscopicity and cloud condensation nuclei activity during the AC3Exp campaign: implications for cloud condensation nuclei parameterization, Atmos. Chem. Phys., 14, 13423-13437, https://doi.org/10.5194/acp-14-13423-2014, 2014.

Zhang, F., Li, Z., Li, Y., Sun, Y., Wang, Z., Li, P., Sun, L., Wang, P., Cribb, M., Zhao, C., Fan, T., Yang, X., and Wang, Q.: Impacts of organic aerosols and its oxidation level on $\mathrm{CCN}$ activity from measurement at a suburban site in China, Atmos. Chem. Phys., 16, 5413-5425, https://doi.org/10.5194/acp-165413-2016, 2016.

Zhang, F., Wang, Y., Peng, J., Ren, J., Zhang, R., Sun, Y., Collin, D., Yang, X., and Li, Z.: Uncertainty in predicting CCN activity of aged and primary aerosols, J. Geophys. Res.-Atmos., 122, 11723-11736, https://doi.org/10.1002/2017JD027058, 2017.

Zhang, R., Khalizov, A. F., Pagels, J., Zhang, D., Xue, H., and McMurry, P. H.: Variability in morphology, hygroscopicity, and op-tical properties of soot aerosols during atmospheric processing, P. Natl. Acad. Sci. USA, 105, 10291-10296, https://doi.org/10.1073/pnas.0804860105, 2008.

Zhang, R., Wang, G., Guo, S. Zamora, M., and Wang, Y.: Formation of urban fine particulate matter, Chem. Rev., 115, 3803-3855, 2015 . 
Zhang, Y., Zhang, Q., Cheng, Y., Su, H., Kecorius, S., Wang, Z., Wu, Z., Hu, M., Zhu, T., Wiedensohler, A., and He, K.: Measuring the morphology and density of internally mixed black carbon with SP2 and VTDMA: new insight into the absorption enhancement of black carbon in the atmosphere, Atmos. Meas. Tech., 9, 1833-1843, https://doi.org/10.5194/amt-9-1833-2016, 2016.
Zhao, J., Du, W., Zhang, Y., Wang, Q., Chen, C., Xu, W., Han, T., Wang, Y., Fu, P., Wang, Z., Li, Z., and Sun, Y.: Insights into aerosol chemistry during the 2015 China Victory Day parade: results from simultaneous measurements at ground level and $260 \mathrm{~m}$ in Beijing, Atmos. Chem. Phys., 17, 3215-3232, https://doi.org/10.5194/acp-17-3215-2017, 2017. 